\title{
Reinforcement Sensitivity Theory Predicts Positive and Negative Affect in Daily Life
}

By: Natalie E. Hundt, Leslie H. Brown, Nathan A. Kimbrel, Molly A. Walsh, Rosemery NelsonGray, Thomas R. Kwapil

Hundt, N.E., Brown, L.H., Kimbrel, N.A., Armistead, M.S., Nelson-Gray, R., \& Kwapil, T.R. (2013). Reinforcement sensitivity theory predicts positive and negative affect in daily life. Personality and Individual Differences, 54(3), 350-354.

Made available courtesy of Elsevier: http://dx.doi.org/10.1016/i.paid.2012.09.021

This is the author's version of a work that was accepted for publication in Personality and Individual Differences. Changes resulting from the publishing process, such as peer review, editing, corrections, structural formatting, and other quality control mechanisms may not be reflected in this document. Changes may have been made to this work since it was submitted for publication. A definitive version was subsequently published in Personality and Individual Differences, [54, 3, (2013)] DOI: 10.1016/j.paid.2012.09.021

\begin{abstract}
:
Laboratory studies of Reinforcement Sensitivity Theory have associated sensitivity to punishment (SP) with negative affect and sensitivity to reward (SR) with positive affect. However, few studies have examined the expression of these systems and their response to cues of reward in daily life. The current study employed experience sampling methodology (ESM) to assess the association of SP and SR with affect and perceptions of situations in daily life. SP was positively associated with negative affect and negatively associated with positive affect in daily life, whereas SR was associated with positive affect and one aspect of negative affect, irritability/anger. Furthermore, high SP participants experienced smaller increases in positive affect and smaller decreases in negative affect in some situations that were perceived as positive, in comparison to low SP participants. In contrast, high SR participants experienced greater decreases in negative affect in some situations that were perceived as positive, in comparison to low SR participants.
\end{abstract}

Keywords: Reinforcement sensitivity | Sensitivity to punishment | Sensitivity to reward| Experience sampling methodology | Affect | Daily life

\section{Article:}

1. Introduction

Reinforcement Sensitivity Theory (RST; Gray, 1991 and Gray and McNaughton, 2000) is a biologically-based personality model proposing that three major brain systems underlie normal mood and appetitive functioning: the Behavioral Approach System (BAS), the Behavioral Inhibition System (BIS), and the Fight-Flight-Freeze System (FFFS). BAS is an appetitive 
system that activates reward-seeking behavior, feelings of elation, and desire for reward (Pickering \& Gray, 1999). Conversely, BIS causes orienting, inhibition, arousal, and passive avoidance to cues of punishment and novel stimuli, and has been conceptualized as an anxiety system (Gray, 1991). Recent RST revisions emphasize that BIS inhibits prepotent conflicting behaviors, assesses risk, and scans memory to resolve goal conflict and activate the FFFS (Corr, 2004 and Gray and McNaughton, 2000). Finally, the FFFS motivates avoidance and escape behaviors and produces the emotion of fear. The combined action of BIS and FFFS produce sensitivity to punishment (SP) whereas BAS produces sensitivity to reward (SR).

According to Gray, SP is related to negative emotion and SR to positive emotion (Gray, 1990 and Gray, 1994). Consistent with these predictions, SP has been associated with selfreported negative affect (Jorm et al., 1999, Leen-Feldner et al., 2004 and Sutton and Davidson, 1997) and negative responses to stressful or punishing situations (e.g., Carver and White, 1994 and Gomez et al., 2000). Conversely, SR has been associated with self-reported positive affect (Carver and White, 1994, Jorm et al., 1999 and Sutton and Davidson, 1997) and positive responses to rewarding situations, including social situations (e.g., Carver and White, 1994, Gomez et al., 2000 and Kashdan and Roberts, 2006). However, SR is also associated with anger and frustration (Carver, 2004 and Harmon-Jones, 2003), perhaps resulting from frustration in the effortful pursuit of goals. SP and SR, respectively, have also been shown to predict negative and positive expectancies of success and judgments about situations and the self (e.g., Avila et al., 1991, Heimpel et al., 2006 and Noguchi et al., 2006).

The previous studies do not, however, indicate how SP and SR are expressed in reaction to experiences in daily life. Experience sampling methodology (ESM) is a method to explore affect and cognitions in the context of daily life experiences. ESM is a within-day, self-assessment technique in which participants are prompted at random intervals to report about their current experiences. ESM offers several advantages over traditional data collection procedures. Specifically, ESM: (1) repeatedly assesses participants in their normal daily environment, thereby enhancing ecological validity; (2) assesses participants' experiences in the moment, thereby minimizing retrospective bias; and (3) allows for an examination of the context of experiences.

Gable, Reis, and Elliot (2000) conducted a daily diary study examining SP and SR in the prediction of affect in response to positive and negative social and achievement events in college students. As hypothesized, SP predicted overall negative affect and SR predicted overall positive affect. SP was also inversely associated with positive affect, a finding that the authors attributed to increased negative affect suppressing positive affect. However, this finding is not predicted by Gray's theory, as SP and SR are orthogonal, and warrants further investigation. In terms of affective reactivity to rewards and punishments, SP predicted greater negative reactivity to stressful events but, contrary to laboratory studies, SR did not predict greater positive reactivity to positive events. Thus, further examination of the relationship of SP and SR to positive affect and affective reactivity to rewarding or pleasant events is necessary. Additionally, this study 
sampled participants only one time per day (e.g., with questions such as "How happy did you feel today?”). Thus, the methodology did not provide a fine-grained temporal analysis and raised the possibility that retrospective bias may have confounded the results.

The current study examined the relation of SP and SR with the experience of affect in daily life and the affective impact of participants' perceptions of current situations in their daily lives. We attempted to measure two kinds of situations that might produce positive affect: interpersonal situations, such as being with close others, and activity situations, such as enjoying, being successful in, and perceiving one's current activity to be important. Based on past research and theory, we predicted that SP would be related to baseline negative affect, whereas SR would be related to baseline positive affect and one aspect of negative affect, specifically irritability/anger. We further predicted that SR would be related to positive affect while perceiving that one's current situation is positive, such as when spending time with close friends, or engaging in an enjoyable or important activity, whereas SP would not be differentially related to affect in these situations.

\section{Method}

\subsection{Participants}

Undergraduates enrolled in an introductory psychology course $(n=180)$ voluntarily participated in this study for course credit. The sample (mean age $=19.6, \mathrm{SD}=3.4$ ) was predominantly female (81\%) and Caucasian (77\%).

\subsection{Materials}

The Sensitivity to Punishment and Sensitivity to Reward Questionnaire (SPSRQ; Torrubia, Avila, Molto, \& Caseras, 2001) is a binary response, self-report measure that contains two 24item scales assessing Sensitivity to Punishment (SP) or BIS (e.g., "Comparing yourself to people you know, are you afraid of many things?”) and Sensitivity to Reward (SR) or BAS (e.g., “Do you generally give preference to those activities that imply an immediate gain?”). Both scales have good reliability and validity (.79 for SR and .87 for SP in the current sample). Distributions of scores on the scales were unimodal and covered the range of possible scores (SP range $=1^{-}$ 24; SR range $=1$-23). Mean scores on SP were $11.3(\mathrm{SD}=5.7)$ and SR were $11.2(\mathrm{SD}=4.6)$, similar to those found in previous studies at this university (e.g., Hundt, Kimbrel, Mitchell, \& Nelson-Gray, 2008).

The 36-item ESM questionnaire inquired about affect and perceptions about activities and social contact at the time of the signal. Sample items included "I feel happy right now," "I like the person(s) I am with right now,” and “I am successful in my current activity.” Participants rated agreement with these statements on a Likert scale from 1 (not at all) to 7 (very much). To increase the chance that our participants would endorse items, we attempted to measure common positive situations that young adults might find themselves in, such as spending time with close 
others, instead of more rare positive situations like getting a better than expected grade or attending party. Fifteen items from the ESM questionnaire were designed and included for use in a different study. Thus, only 21 of the 36 ESM questions (13 affect questions and 8 situation questions) were analyzed in the present study.

In order to reduce the number of analyses and the rate of Type I error, composite variables were constructed based upon principal components analysis (PCA). A PCA of the 13 affect variables with a promax oblique rotation extracted two factors with eigenvalues above 1 that together explained $69.8 \%$ of the variance: a negative affect factor (eigenvalue 5.8), with high loadings of the individual items frustrated, angry, irritable,sad, uncertain, gloomy, self-conscious, and anxious; and a positive affect factor (eigenvalue $=3.7$ ), with high loadings from items excited, enthusiastic, energetic, happy, and confident ( Table 1). Cross loadings were minimal (below .30) and the two factors were not significantly correlated $(r=.02, p=.58$ ).

Table 1. Principal component analysis of affect variables.

\begin{tabular}{|l|l|l|}
\hline Variable & NA factor loading & PA factor loading \\
\hline Frustrated &. $\mathbf{9 2}$ & -.06 \\
\hline Angry & $\mathbf{. 9 0}$ & -.06 \\
\hline Irritable &. $\mathbf{8 7}$ & -.04 \\
\hline Sad & $\mathbf{. 8 7}$ & -.17 \\
\hline Uncertain &. $\mathbf{8 5}$ & .01 \\
\hline Gloomy &. $\mathbf{8 6}$ & -.14 \\
\hline Self-conscious &. $\mathbf{7 2}$ & .08 \\
\hline Anxious & $\mathbf{. 6 7}$ & .29 \\
\hline Excited & .11 & $\mathbf{. 9 2}$ \\
\hline Enthusiastic & .15 & $\mathbf{. 9 1}$ \\
\hline Energetic & .10 & $\mathbf{. 9 0}$ \\
\hline Happy & -.29 & $\mathbf{. 8 3}$ \\
\hline Confident & -.29 & \\
\hline
\end{tabular}

Note: Bolded loadings are above .30 . 
A PCA was also conducted on the variables regarding perceptions of the current situation. Three factors with eigenvalues over 1 emerged, together explaining $73.0 \%$ of the variance. The first factor (eigenvalue $=3.8$ ) had high loadings from the following items: I like the person(s) I am with, I am important to the person(s) I'm with, and I am close to the person(s) I'm with. This factor was labeled Interpersonal Closeness. The next factor (eigenvalue $=1.6$ ) had high loadings from the items I'm successful in my current activity, I have the ability to do my current activity, and I like my current activity. This factor was labeled Successful Activity. The third factor (eigenvalue $=1.3$ ) had high loadings from the items My current activity is important and My current activity takes effort. This factor was labeled Important/Effortful Activity. Although there are some substantial cross-loadings, these are as would be expected. For example, liking one's activity loads substantially on the interpersonal closeness factor, indicating that participants reported liking their activity when they were with close others.

\subsection{Procedure}

Participants were administered the SPSRQ in a group screening at the beginning of the semester and later volunteered to participate in the ESM part of the study. ESM data were collected on personal digital assistants (PDAs; Palm Pilot Zire model; Palm, Sunnyvale, CA) using iESP software (Intel Experience Sampling Program; Intel Research Seattle \& the University of Washington Computer Science and Engineering Department). Participants attended an information session in which experimenters provided PDAs and described the procedures. The PDAs randomly signaled the participants to complete the ESM questionnaire 8 times per day for seven days. A signal occurred at random during each 90 min time window between noon and midnight. Participants had 5 min to initiate their responses following the signal, and their responses were recorded and time-stamped by the PDA. In addition to course credit, participants were also placed in a drawing for gift certificates if they completed at least 70\% of the ESM questionnaires. Participants completed an average of 40.7 questionnaires (SD $=10.6)$ out of a maximum of 56 questionnaires, or $73 \%$.

\subsection{Data analysis}

ESM data have a hierarchical structure in which ratings are nested within days which are nested within subjects, representing a 3-level model. The multilevel data were analyzed with SAS 9.3. Two types of analyses were computed. First, the direct relationships of SP and SR with affect, cognition, and behavior in daily life were examined with the equation yijk $=\mathrm{b}_{0}+\mathrm{b}_{1} * \mathrm{SP}+\mathrm{b}_{2} * \mathrm{SR}+\mathrm{b}_{3} * \mathrm{SP}+\mathrm{SR}+\mathrm{U}_{\mathrm{i}}+\mathrm{eij} k$. Second, cross-level interactions (Nezlek, 2001) examined the extent to which relationships among ESM variables (e.g., social contact and positive affect) varied across levels of SP and SR, using the equationyijk $=\mathrm{b}_{0}+\mathrm{b}_{1} * \mathrm{SP}+\mathrm{b}_{2} * \mathrm{SR}+\mathrm{b}_{3} * \mathrm{SP}+\mathrm{SR}+\mathrm{bij}_{1} *$ Liking Person+bij ${ }_{2} *$ Successful Activity...bij $j_{16} * \mathrm{SP} * \mathrm{SR} *$ Effortful Activity $+\mathrm{U}_{\mathrm{i}}+\mathrm{eijk}$. For example, cross-level interactions examined whether the relationship between positive affect and social contact differed for people higher versus lower in SP and SR. If SP or SR was significant, it would explain variability in the 
within-person slopes of the ESM measures. Following the recommendations of Cohen, Cohen, and West (2003) and Luke (2004), we grand-mean centered the scores for SP and SR. ESM predictors were group mean (within-person) centered.

\section{Results}

Scores on the SP and SR scales were correlated, $r=.23, p<.05$, in the present study. SR scores, but not SP scores, were negatively associated with the number of ESM questionnaires completed, $r=-.17, p<.05$.

\subsection{Affect and SP and SR in daily life}

Table 2 presents the associations of SP and SR with self-reported affect, appraisals of the current situation, and social contact in daily life. Consistent with the hypotheses, SP was associated with experiencing negative affect in daily life, whereas SR was associated with experiencing positive affect; however, SP was also negatively associated with experiencing positive affect, whereas SR was positively associated with experiencing negative affect. One potential explanation for these findings may be differential relationships of SP and SR to different types of positive and negative affect. In particular, SR has been shown to be associated with anger and frustration (Carver, 2004), but not sadness. To further examine these findings, we examined the relationships of SR with specific types of negative affect. These results indicated that SR was positively associated with feeling irritable $(\gamma=.10, \mathrm{SE}=.03, p=.02)$, frustrated $(\gamma=.09$, $\mathrm{SE}=.03, p=.03$ ), and angry $(\gamma=.11, \mathrm{SE}=.04, p=.03$ ), but not sad or gloomy (both $p$ ns).

Table 2. Principal component analysis of situation/activity variables.

\begin{tabular}{|l|l|l|l|}
\hline Variable & $\begin{array}{l}\text { Interpersonal } \\
\text { closeness loading }\end{array}$ & $\begin{array}{l}\text { Successful activity } \\
\text { loading }\end{array}$ & $\begin{array}{l}\text { Important/ effortful } \\
\text { activity loading }\end{array}$ \\
\hline $\begin{array}{l}\text { I like the person(s) I am } \\
\text { with }\end{array}$ & $\mathbf{. 9 5}$ & $\mathbf{. 4 0}$ & .22 \\
\hline $\begin{array}{l}\text { I am important to the } \\
\text { person(s) I'm with }\end{array}$ & $\mathbf{. 9 6}$ & $\mathbf{. 4 1}$ & .24 \\
\hline $\begin{array}{l}\text { I am close to the } \\
\text { person(s) I'm with }\end{array}$ & $\mathbf{. 9 7}$ & .35 & .23 \\
\hline $\begin{array}{l}\text { I'm successful in my } \\
\text { current activity }\end{array}$ & .34 & $\mathbf{. 9 5}$ & .08 \\
\hline $\begin{array}{l}\text { I have the ability to do my } \\
\text { current activity }\end{array}$ & .28 & $\mathbf{. 9 2}$ & .06 \\
\hline
\end{tabular}




\begin{tabular}{|l|l|l|l|}
\hline I like my current activity & $\mathbf{. 5 0}$ & $\mathbf{. 6 1}$ & .27 \\
\hline $\begin{array}{l}\text { My current activity is } \\
\text { important }\end{array}$ & .29 & .28 & $\mathbf{. 8 8}$ \\
\hline $\begin{array}{l}\text { My current activity takes } \\
\text { effort }\end{array}$ & .09 & -.08 & $\mathbf{. 8 9}$ \\
\hline
\end{tabular}

Note: Bolded loadings are above .30 .

In terms of appraisal of the current situation, SP was negatively associated with perceptions of success, such that individuals high in SP perceived that they were less successful in their current activity. SR, on the other hand, was negatively associated with perceptions of interpersonal closeness, indicating that individuals higher on SR rated themselves as less close to their current companions. No interactions between SP and SR were significant (Table 3).

Table 3. Relationships of SP and SR with daily affect and appraisals of situations.

\begin{tabular}{|l|l|l|l|}
\hline Criterion (ESM composite or item) & SP & SR & SP $\times$ SR \\
\cline { 2 - 4 } & $\gamma(\mathrm{SE})$ & $\gamma(\mathrm{SE})$ & $\gamma(\mathrm{SE})$ \\
\hline NA & $.16(.04)^{* *}$ & $.13(.05)^{*}$ & $.04(.04)$ \\
\hline PA & $-.11(.04)^{*}$ & $.09(.04)^{*}$ & $-.03(.04)$ \\
\hline Interpersonal closeness factor & $-.07(.04)$ & $-.08(.04)^{*}$ & $.01(.03)$ \\
\hline Successful activity factor & $-.15(.04)^{* *}$ & $-.03(.04)$ & $.00(.03)$ \\
\hline Important/Effortful activity factor & $-.02(.03)$ & $.01(.04)$ & $.00(.03)$ \\
\hline
\end{tabular}

${ }^{*} p<.05 .{ }^{* *} p<.01$.

\subsection{Cross-level interactions}

Cross-level interactions were calculated to examine the effect of context on the expression of SP and SR in daily life (Table 4). Cross-level interactions predicting negative affect were examined first. Although there was a significant two-way interaction between SP and interpersonal closeness, a significant three-way interaction between SP, SR, and interpersonal closeness was also observed. Therefore, only the three-way interaction is discussed here. Overall, regardless of SP and SR, increasing interpersonal closeness was associated with decreased negative affect. The interaction with SP and SR, however, indicates that as both SP and SR decrease, interpersonal closeness has less of an effect upon negative affect, whereas as SP and SR increase, more interpersonal closeness is associated with a stronger decrease in negative affect (Fig. 1). SP also interacted with perceiving that one is successful at one's current activity in the prediction of 
negative affect. In general, success was associated with less negative affect; however, as SP increased, the effect of successful activity was reduced. Thus, individuals high on SP who perceived that they were successful continued to experience more negative affect than their low SP peers.SR also interacted with success at one's current activity in the prediction of negative affect such that as SR increased, the effect of successful activity in reducing negative affect was stronger.

Table 4. Effects of SP and SR on affective reactions to appraisals of situations.

\begin{tabular}{|c|c|c|c|c|c|}
\hline $\begin{array}{l}\text { ESM } \\
\text { criterion }\end{array}$ & ESM predictor & $\begin{array}{l}\text { Relation of ESM predictor } \\
\text { and criterion }\end{array}$ & SP & SR & $\mathrm{SP} \times \mathrm{SR}$ \\
\hline & & $\gamma(\mathrm{SE})$ & $\gamma(\mathrm{SE})$ & $\gamma(\mathrm{SE})$ & $\gamma(\mathrm{SE})$ \\
\hline NA & $\begin{array}{l}\text { Interpersonal } \\
\text { closeness }\end{array}$ & $-.07(.01)^{* * *}$ & $\begin{array}{l}-.03 \\
(.01)^{*}\end{array}$ & $.00(.01)$ & $\begin{array}{l}-.03 \\
(.01)^{*}\end{array}$ \\
\hline NA & $\begin{array}{l}\text { Successful at } \\
\text { activity }\end{array}$ & $-.27(.01)^{* * *}$ & $\begin{array}{l}.03 \\
(.01)^{*}\end{array}$ & $\begin{array}{l}-.03 \\
(.01)^{*}\end{array}$ & $.00(.01)$ \\
\hline NA & Effortful activity & $.01(.01)$ & $.01(.01)$ & $\begin{array}{l}-.02 \\
(.01)\end{array}$ & $\begin{array}{l}-.01 \\
(.01)\end{array}$ \\
\hline PA & $\begin{array}{l}\text { Interpersonal } \\
\text { closeness }\end{array}$ & $.10(.01)^{* * * *}$ & $.02(.01)$ & $.01(.02)$ & $.00(.01)$ \\
\hline PA & $\begin{array}{l}\text { Successful at } \\
\text { activity }\end{array}$ & $.24(.02)^{* * *}$ & $\begin{array}{l}-.02 \\
(.02)\end{array}$ & $.00(.01)$ & $.00(.01)$ \\
\hline PA & Effortful activity & $.05(.01)^{* *}$ & $\begin{array}{l}-.04 \\
(.01)^{*}\end{array}$ & $.02(.01)$ & $.02(.01)$ \\
\hline
\end{tabular}




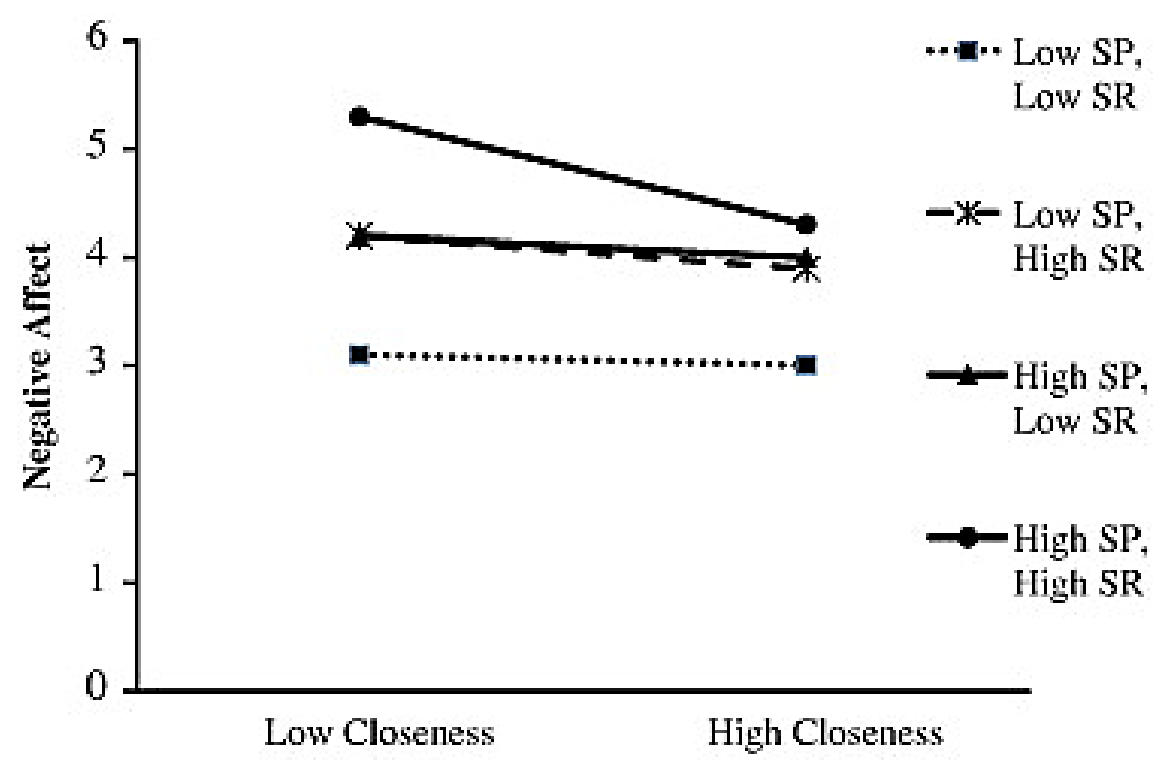

Fig. 1. Negative affect as a function of interpersonal closeness.

Next, we examined cross-level interactions predicting positive affect. These results indicated an interaction between SP and the perception that one's current activity was effortful and important. In general, effortful and important activities were associated with positive affect; however, as SP increased, the effect of such activities on increasing PA weakens. In other words, high SP participants are more reactive to effortful and important activities and experience less PA in comparison to their low SP peers.

\section{Discussion}

The present study examined the associations of SP and SR with daily affect and reactivity to cues of reward. Consistent with previous research (e.g., Gable et al., 2000, Gomez et al., 2000, LeenFeldner et al., 2004 and Sutton and Davidson, 1997), we found that SP predicted daily negative affect. Additionally, SP was negatively associated with daily positive affect. Although this finding would not be predicted by the original RST, it is consistent with the only previous daily diary study (Gable et al., 2000) and thus lends support to the idea that SP may suppress positive affect in daily life. This finding may be consistent with the Joint Subsystems Hypothesis (JSH; Corr, 2001), which suggests that SP and SR may not exert independent effects. Overall, people high in SP appear to experience more negative affect and less positive affect in their daily lives.

SR, on the other hand, was associated with experiencing more positive affect in daily life. This is consistent with RST, a multitude of laboratory studies, and one previous daily diary study (e.g., Carver and White, 1994 and Gable et al., 2000). Contrary to our hypotheses, SR was also associated with experiencing negative affect. However, follow-up analyses indicated that SR was strongly associated with certain types of negative affect, primarily anger, frustration, and irritability, but not with sadness or gloominess. The association of SR with anger is consistent 
with Carver's (2004) hypothesis that people high in SR may experience irritability with goal frustration and is supported by other research finding BAS to be associated with anger (e.g., Harmon-Jones, 2003).

SP and SR were associated with a variety of appraisals of one's current situation. For example, SR was associated with reporting less interpersonal closeness to people in one's current environment. This may reflect that high SR individuals spend more time with a broader range of acquaintances or strangers, consistent with gregariousness or extraversion, which is related to SR (Smits \& Boeck, 2006). SP was associated with perceiving that one is less successful at one's current activity. This is consistent with previous studies showing that SP is associated with negative judgments about situations and the self (Heimpel et al., 2006 and Noguchi et al., 2006).

In cross-level interactions predicting negative affect, SP and SR interacted with interpersonal closeness such that, as both SP and SR decreased, interpersonal closeness had less of an effect upon negative affect. In contrast, as SP and SR increased, interpersonal closeness was associated with a stronger decrease in negative affect. This indicates that individuals who are low in both SP and SR are less affected by being with close others, whereas individuals who are high in both personality factors are more affected. Additionally, high SP appeared to dampen the negative affect-reducing function of perceiving that one is successful in one's current activity. High SR, on the other hand, appeared to strengthen the negative affect reducing function of with perceiving that one is successful. Overall, these cross-level interactions indicate that SR is associated with a greater reduction in negative affect during situations that are perceived as positive, whereas SP is associated with less reduction in negative affect during situations that are perceived as positive.

In cross-level interactions predicting positive affect, high SP was associated with smaller increases in positive affect when one perceives that an activity is effortful/important and smaller increases in positive affect when one perceives that one's activity is the center of attention, in comparison to low SP. There were no interactions of SR with perceptions of the situation in cross-level interactions predicting positive affect, contrary to our hypotheses. This finding is also at odds with laboratory studies showing increased positive affect in rewarding circumstances (e.g. Carver and White, 1994 and Gomez et al., 2000). One possible explanation for this discrepancy is that the nature of rewards in laboratory tasks (money, course credit) differs substantially from the rewards assessed in this study (enjoyment of and success in one's activity, being with close friends). The naturally occurring rewards assessed in this study frequently encountered and would be expected in daily life. As such, they might not be rewarding enough to generate significant increases in positive affect, as there is evidence that expected rewards may not be experienced as particularly rewarding and receiving less than the expected reward may be experienced as punishment (Corr, 2002). In contrast, rewards in laboratory studies might be perceived as more rewarding because they are unexpected and little or no habituation has taken place. 
Overall, these results suggest that SP is related to increased baseline negative affect and decreased baseline positive affect, whereas SR is related to increased positive affect and increased anger/frustration (but not sadness/gloominess). These relationships are not fully predicted by RST, but may be consistent with Corr's (2001) joint-subsystems hypothesis (JSH), which proposes that SP and SR should not be examined separately because their effects upon behavior are interdependent upon each other. For example, low SP can magnify the effects of high SR. Future research should more fully examine the relation of SP with positive affect and SR with negative affect in daily life.

\subsection{Strengths and limitations}

Limitations of the current study include the limited number of questions asked at each time point and the lack of assessment of negative events or situations. However, given that participants were completing questionnaires up to 8 times daily, the questionnaire had to be brief to avoid overtaxing participants. Future studies should examine positive and negative affect in relation to perceiving that one is in a negative or aversive situation. A major strength of the study was that ESM allowed for an examination of the effects of SP and SR under naturally-occurring environmental conditions. As such, ESM appears to be a promising method for furthering our understanding of the impact of SP and SR on daily life.

\section{References}

Avila, C., Molto, J., Segarra, P., \& Torrubia, R. (1991). Sensitivity to conditioned or unconditioned stimuli: What is the mechanism underlying passive avoidance deficits in extraverts? Journal of Research in Personality, 29, 373-394.

Carver, C. S. (2004). Negative affects deriving from the behavioral approach system. Emotion, 4, $3-22$.

Carver, C. S., \& White, T. L. (1994). Behavioral inhibition, behavioral activation, and affective responses to impending reward and punishment: The BIS/BAS scales.

Journal of Personality and Social Psychology, 67, 319-333. Cohen, J., Cohen, P., \& West, S. G. (2003). Applied multiple regression/correlation analysis for the behavioral sciences (3rd ed.). Mahwah, NJ: Erlbaum.

Corr, P. J. (2001). Testing problems in J. A. Gray's personality theory: A commentary on Matthews and Gilliland (1999). Personality and Individual Differences, 30, 333-352.

Corr, P. J. (2002). J.A. Gray's reinforcement sensitivity theory and frustrative nonreward: A theoretical note on expectancies in reactions to rewarding stimuli. Personality and Individual Differences, 32, 1247-1253. 
Corr, P. J. (2004). Reinforcement sensitivity theory and personality. Neuroscience and Biobehavioral Reviews, 28, 317-332.

Gable, S. L., Reis, H. T., \& Elliot, A. J. (2000). Behavioral activation and inhibition in everyday life. Journal of Personality and Social Psychology, 78, 1135-1149.

Gomez, R., Cooper, A., \& Gomez, A. (2000). Susceptibility to positive and negative mood states: Test of Eysenck’s, Gray’s, and Newman’s theories. Personality and Individual Differences, 29, 351-366.

Gray, J. A. (1990). Brain systems that mediate both emotion and cognition. Cognition and Emotion, 4, 269-288.

Gray, J. A. (1991). Neural systems, emotion, and personality. In J. Madden (Ed.), Neurobiology of Learning, Emotion, and Affect (pp. 273-306). New York: Raven Press.

Gray, J. A. (1994). Framework for taxonomy of psychiatric disorder. In S. M. H. van Goozen, V. E. van de Poll, \& J. A. Sergeant (Eds.), Emotions: Essays on emotion theory (pp. 29-60). Hillsdale, NJ: Lawrence Erlbaum Associates.

Gray, J. A., \& McNaughton, N. (2000). The neuropsychology of anxiety (2nd ed.). New York, NY: Oxford University Press.

Harmon-Jones, E. (2003). Anger and the behavioral approach system. Personality and Individual Differences, 35(5), 995-1005.

Heimpel, S. A., Elliot, A. J., \& Wood, J. V. (2006). Basic personality dispositions, self-esteem, and personal goals: An approach-avoidance analysis. Journal of Personality, 74, 1293-1320.

Hundt, N. E., Kimbrel, N. A., Mitchell, J. T., \& Nelson-Gray, R. O. (2008). High BAS, but not low BIS, predicts externalizing symptoms in adults. Personality and Individual Differences, 44, 565-575.

Jorm, A. F., Christensen, H., \& Henderson, A. S. (1999). Using the BIS/BAS scales to measure behavioral inhibition and behavioural activation: Factor structure, validity and norms in a large community sample. Personality and Individual Differences, 26, 49-58.

Kashdan, T. B., \& Roberts, J. F. (2006). Affective outcomes in superficial and intimate interactions: Roles of social anxiety and curiosity. Journal of Research in Personality, 40, 140167.

Leen-Feldner, E. W., Zvolensky, M. J., Feldner, M. T., \& Lejuez, C. W. (2004). Behavioral inhibition: Relation to negative emotion regulation and reactivity. Personality and Individual Difference, 36, 1235-1247. 
Luke, D. A. (2004). Multilevel modeling. Thousand Oaks, CA: Sage.

Nezlek, J. B. (2001). Multilevel random coefficient analyses of event and intervalcontingent data in social and personality psychology research. Personality and Social Psychology Bulletin, 27, 771-785.

Noguchi, K., Gohm, C. L., \& Dalsky, D. J. (2006). Cognitive tendencies of focusing on positive and negative information. Journal of Research in Personality, 40,891-910.

Pickering, A. D., \& Gray, J. A. (1999). The neuroscience of personality. In L. A. Pervin \& O. P. John (Eds.), Handbook of personality: Theory and research (2nd ed., pp. 277-299). New York: Guilford Press.

Smits, J. M., \& Boeck, P. D. (2006). From BIS/BAS to the big five. European Journal of Personality, 20, 255-270.

Sutton, S. K., \& Davidson, R. J. (1997). Prefrontal brain asymmetry: A biological substrate of the behavioral approach and inhibition systems. Psychological Science, 8, 204-210.

Torrubia, R., Avila, C., Molto, J., \& Caseras, X. (2001). The sensitivity to punishment and sensitivity to reward questionnaire (SRSRQ) as a measure of gray's anxiety and impulsivity dimensions. Personality and Individual Differences, 31, 837-862. 